\title{
Inpatients had mostly negative experiences of seclusion during short term treatment in a mental health facility
}

Meehan T, Vermeer C, Windsor C. Patients'perceptions of seclusion: a qualitative investigation.J Adv Nurs 2000 Feb;31:370-7.

\section{QUESTION: How do patients experience seclusion during short term inpatient treatment in a mental health facility?}

Design

Semi structured interviews.

Setting

2 open, acute care units of a large tertiary mental health facility in Queensland, Australia.

\section{Patients}

12 patients ( $58 \%$ men) who were $18-52$ years of age and were secluded in the previous 7 days (mean duration $3.4 \mathrm{~h})$.

\section{Methods}

Semi structured, thematically organised interviews were audiotaped and transcribed. Transcripts were checked for errors against the audiotaped versions and were analysed using the process of meaning categorisation. Themes were identified and coded to produce categories. All members of the research team agreed on the final categorisations. These broad categories were further analysed, and themes were used to reflect patients' experiences of seclusion.

\section{Main findings}

5 recurrent themes emerged. (1) Patients described the use of seclusion. Some patients thought that seclusion was used inappropriately and that the seclusion period was of more benefit to staff than to patients. Most patients felt that the use of force to seclude patients, remove their clothing and personal belongings, and give medication was unjustified. Some patients associated seclusion with punishment. Other patients viewed seclusion as a safe environment in which they could gain control over their actions. Most patients felt undeserving of seclusion and identified various alternatives to being locked in a room. (2) The emotional impact of seclusion included anger, which was primarily directed at staff; powerlessness, in a system that took complete control; disempowerment, described as humiliation and an inability to change anything; and fear (of confined spaces, injections, and medication), which did not dissipate once patients were released from the seclusion room. (3) Sensory deprivation was a common experience. Patients described feelings of depression, a heightened awareness of sounds, difficulty in judging time, feelings of loss of control, and dysfunctional thought patterns. Patients often made suggestions about putting items such as paintings in the seclusion room to help them to cope with the boredom and isolation. (4) Patients used various strategies to help them to maintain control while in seclusion (eg, talking to themselves to break the silence or being quiet so that the seclusion period was not prolonged). (5) Staff-patient interaction during and after the seclusion period was a main source of dissatisfaction for all patients. Most patients felt that more effective communication about seclusion and specific input about behaviours that warrant its use would be preventive. Patients reported that staff communication during and after the seclusion period would have been helpful and expressed the need for a debriefing period after seclusion. Patients felt that they lost claim to any individuality or rights once they were in seclusion.

\section{Conclusions}

The experience of patients who were secluded during short term inpatient treatment in a mental health facility was described using 5 themes. Patients' experiences were mostly negative, and they expressed the desire for more information, better interaction with staff, more attention to privacy, and effective debriefing after seclusion.

\section{COMMENTARY}

Seclusion is a reality in many psychiatric settings, a fact that causes concern for both staff and patients. The past decade has seen a particular interest in patients' perceptions of the seclusion experience, and their perceptions are primarily negative. The results presented by Meehan $e t$ al are consistent with findings from other studies in various locations..$^{1-3}$

The study by Meehan $e t$ al will be helpful for clinicians working in psychiatric units because it highlights the often disempowering, negative, long lasting effect of being secluded. The participants had helpful suggestions for clinicians, which could serve as possible therapeutic interventions. The staff-patient interaction was a major source of dissatisfaction, and patients felt they lacked information before and during the seclusion. They requested being better informed about rules and consequences and expectations that would lead to the termination of seclusion. Most importantly, they expressed a desire for debriefing after seclusion, including preventive strategies. Implementing such suggestions is possible in any setting and would have the potential to improve patients' feelings of empowerment and trust.

Recent research has focused on interventions such as staff training which may lead to a decrease in seclusion usage or length of time in seclusion. ${ }^{4}$ Meehan $e t a l$ s research suggests work that can also be done to decrease the negative effect of the seclusion experience when it is considered necessary. This is an important contribution.

Helen Kirkpatrick, RN, MScN, MEd, RPRP Hamilton Psychiatric Hospital Hamilton, Ontario, Canada

1 Lendemeijer B, Shortridge-Baggett L. The use of seclusion in psychiatry: a literature review. Sch Inq Nurs Pract 1997;11:299-315.

2 Martinez RJ, Grimm M, Adamson M. From the other side of the door: patient views of seclusion. J Psychosoc Nurs Ment Health Serv 1999;37:13-22.

3 Ray NK, Myers KJ, Rappaport ME. Patient perspectives on restraint and seclusion experiences: a survey of former patients of New York State psychiatric facilities. Psychiatric Rehabilitation Journal 1996;20:11-8.

4 Forster PL, Cavness C, Phelps MA. Staff training decreases use of seclusion and restraint in an acute psychiatric hospital. Arch Psychiatr Nurs 1999;13:269-71. 